\title{
Adult separation anxiety in pregnancy: how common is it?
}

This article was published in the following Dove Press journal:

International Journal of Women's Health

23 May 2012

Number of times this article has been viewed

\author{
Valsamma Eapen ${ }^{1,2}$ \\ Derrick M Silove ${ }^{1,3}$ \\ Deborah Johnston ${ }^{1,2}$ \\ Alex Apler ${ }^{1,2}$ \\ Susan Rees ${ }^{1,3}$ \\ 'School of Psychiatry, University \\ of New South Wales, Sydney, \\ ${ }^{2}$ Infant Child and Adolescent Mental \\ Health Service, Academic Unit \\ of Child Psychiatry, ${ }^{3}$ Center for \\ Population Mental Health Research, \\ Psychiatry Research and Teaching \\ Unit, South West Sydney Local Health \\ District, Liverpool, NSW, Australia
}

Correspondence: Valsamma Eapen Academic Unit of Child Psychiatry, Infant Child Adult Mental Health Service, Mental Health Center, LI Liverpool Hospital, Elizabeth Street, Liverpool, NSW 2170 , Australia

$\mathrm{Tel}+61296164205$

Fax +6I $2960 \mid 2773$

Email v.eapen@unsw.edu.au
Abstract: The present study, the first to examine adult separation anxiety (ASA) in the context of pregnancy, found that ASA is a common yet unrecognized condition. Women attending an antenatal clinic were evaluated for the presence of ASA. A quarter of the women reached an established symptom threshold for ASA, with significantly more primigravida women $(P=0.003)$ identified as having the problem. There were no significant differences in the sociodemographic characteristics between those with and without ASA. Around one-third acknowledged that ASA was causing significant impairment in day-to-day functioning, suggesting the clinical importance of the pattern. Further research is indicated to explore this clinical entity and its impact on maternal and infant psychosocial wellbeing.

Keywords: separation anxiety, perinatal mental health, prevalence, sociodemographic factors.

\section{Introduction}

Anxiety in expectant mothers may affect the quality of the mother-infant interaction, exerting an important impact on the later development, competencies, and mental health of the infant. ${ }^{1}$ While separation anxiety disorder is a well-established form of anxiety in young persons, both its occurrence and continuity into adulthood have only been recently documented..$^{2-5}$ As a result of emerging evidence from clinical and community studies, ${ }^{6,7}$ the category of adult separation anxiety (ASA) disorder was included for the first time in a national epidemiology study, the National Comorbidity Study Replication (NCS-R) in the United States. The NCS-R study found a high lifetime prevalence of childhood and adult separation anxiety disorder of $4.1 \%$ and $6.6 \%$, respectively, and a 12 -month prevalence of $1.9 \% .{ }^{8}$ If this pattern is consistent in pregnancy, the prevalence of ASA would be higher than the prevalence of panic disorder (1.4\%) and obsessive compulsive disorder $(1.3 \%)$ and lower than the prevalence of generalized anxiety disorder $(8.5 \%) .{ }^{9}$

ASA is analogous to the symptoms manifested in childhood separation anxiety disorder apart from the expected differences associated with maturation (eg, adults avoiding work for a fear of leaving home, while children avoid school). Affected adults experience intense anxiety about separation from their close attachment figures, fearing that harm might befall themselves or their loved ones, and they engage in various strategies to avoid separation. ${ }^{4}$ Life cycle changes and transitions are important catalysts in triggering mental health problems and this pattern is likely to pertain to ASA. In this regard, pregnancy has been described as a psychological watershed for a woman as the transition to motherhood demands changes in her role and status: becoming a 
different sort of child to her own parents; becoming a mother to her fetus/baby; and/or a different sort of a mother if she already has other children. ${ }^{10}$ While feeling anxious about separation may be normal and desirable when caring for young children, excessive separation anxiety in the mother may be maladaptive and detrimental to the woman's mental health and to the development and behavior of the infant. There are compelling reasons, therefore, to anticipate that mothers who have preexisting and exaggerated fears about the safety and health of those close to them may experience exacerbations of ASA symptoms during and after childbirth, particularly amongst first time mothers.

The data from the NCS-R study is relevant to the perinatal period since it indicates that ASA may occur for the first time in adult life, with approximately two-thirds of cases reporting onset in late adolescence or in their early twenties and $80 \%$ of cases occurring prior to 28 years of age. ${ }^{8}$ This suggests that the peak age of onset may coincide with the childbearing period in women. The purpose of this study was to examine the manifestations of ASA in a group of women attending an antenatal clinic, with the aim of obtaining a general estimate of the prevalence of the problem and documenting its associations with relevant sociodemographic data among pregnant women in the Australian setting.

\section{Methods}

The study sample consisted of women attending the antenatal clinic at Liverpool hospital in South West Sydney between November 2009 and April 2011. Research personnel randomly chose two to three clinic days per week to recruit participants to the study and all women attending the antenatal clinic on these days were approached. Women who were younger than 18 years of age, distressed, unwell, disabled, or lacking sufficient English comprehension such that they could not provide informed consent were excluded. The recruitment details are given in Figure 1.

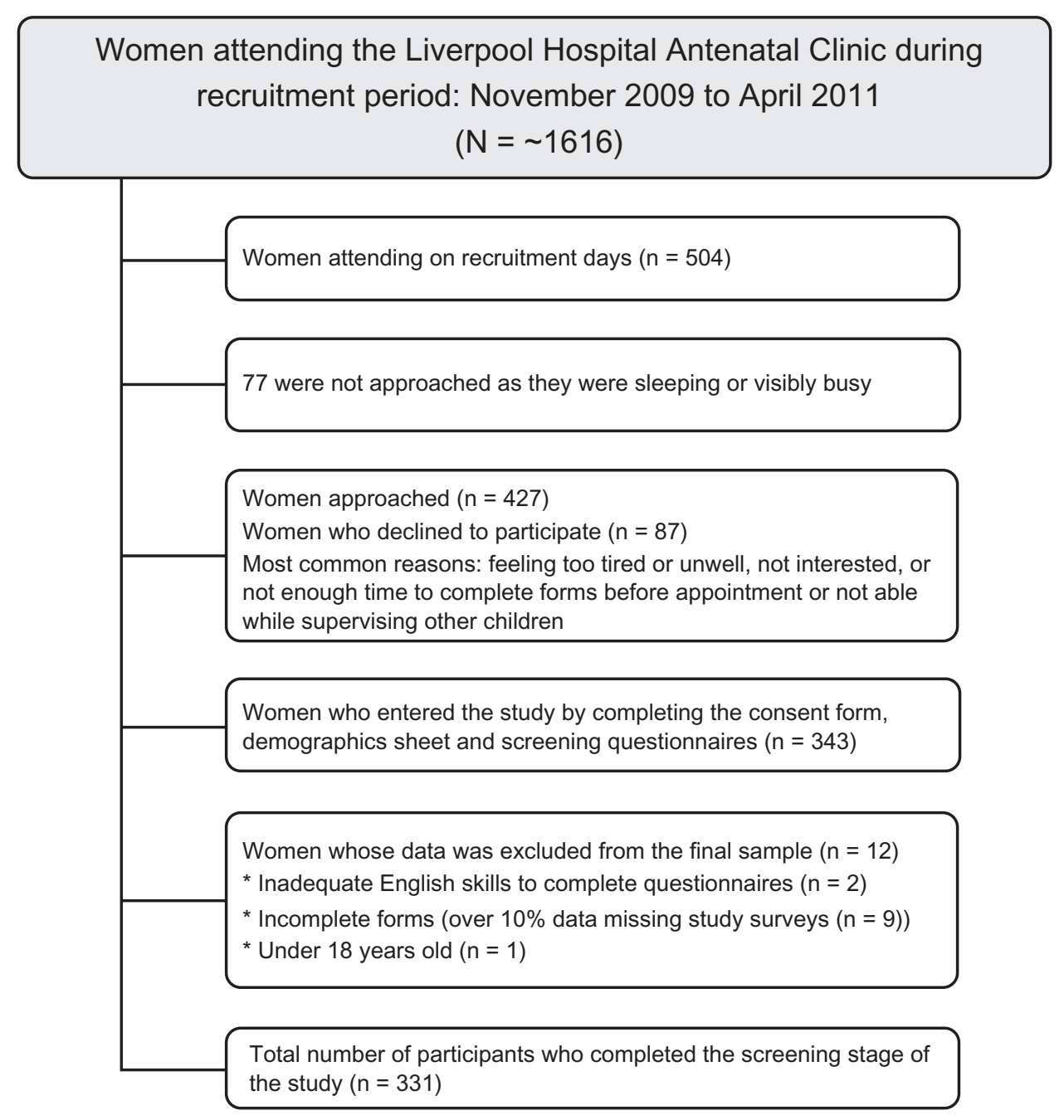

Figure I Recruitment flow. 


\section{Subjects}

Of the 427 women who were invited to participate, 343 $(80.3 \%)$ entered the study by providing informed consent, filling in a sociodemographic form, and completing the self-report ASA Scale (ASA-27). The study was approved by our Institutional Ethics Committee and all participants gave informed consent.

\section{Measures}

ASA-27 is a 27-item self-report questionnaire covering symptoms of separation anxiety experienced after the age of 18 years, with each item rated on a scale from zero (this never happens) to three (this happens very often). ${ }^{11}$ The items were developed as adult equivalents of childhood separation anxiety disorder Diagnostic and Statistical Manual of Mental Disorders (fourth edition) symptoms. The measure has sound internal consistency (Cronbach's alpha $=0.89)$ and test-retest reliability $(\mathrm{r}=0.86$, $P<0.001) .{ }^{3}$ Scores range from zero to 81 with a higher score indicating a higher probability of separation anxiety. A cutoff score of 22 or more has been determined as indicative of the presence of ASA on a receiver operating characteristic analysis in which the questionnaire was compared with a semistructured clinical interview (the ASA Semistructured Interview) modeled on the Structured Clinical Interview for Diagnostic and Statistical Manual of Mental Disorders (fourth edition). ${ }^{12} \mathrm{~A}$ high area under the curve value of 0.9 indicated an excellent level of concordance between the two instruments.

In the present study, an impairment question was added to the end of the questionnaire, allowing respondents to indicate the extent to which their functioning had been impaired by the separation anxiety symptoms they had experienced. A small subset (7\%) of the participants was further assessed using the Composite International Diagnostic Interview module for separation anxiety disorder, which explores symptoms experienced during childhood and adulthood including age of onset. Using the Composite International Diagnostic Interview module as the gold standard for a diagnosis of ASA, the ASA-27 was found to have a sensitivity of $91.7 \%$, a specificity of $81.8 \%$, and an area under the curve of 0.904 , which suggested a high level of convergence between the two measures.

A semistructured demographic form was used to collect information about the participant's age, ethnic background, marital status, education, occupation, and number of other children.

\section{Results}

Of the 343 women who entered the study, twelve women did not meet eligibility criteria or had more than $10 \%$ of data missing on their questionnaires. They were subsequently excluded from the study, leaving a final sample of 331 subjects for analysis. The maximum rate of missing data on respondent questionnaires was $7.5 \%$ (two questions). Multiple imputation was used to impute missing data. Table 1 details the sociodemographic characteristics of the sample. The mean age of the sample was 29 years and $82 \%$ were married. For about one-third of the women this was their first pregnancy. The sample was ethnically diverse with $60.7 \%$ of the sample listing an ethnic background other than Australian. The majority (95\%) had completed 10 years or more of education with a quarter having a university degree and one-third holding a professional position. A quarter of the women were in full-time employment. Of the sample, $24.5 \%$ was found to have broadly defined ASA as indicated by a score above the cutoff on ASA-27. Age of onset data, which was available for a subset of subjects, revealed that $36 \%$ of those with ASA had an adult onset of symptoms; $60 \%$ of whom reported the onset to be during pregnancy. None of these women were identified as having ASA by their health care providers prior to participation in this study. There were no significant differences between those with ASA and without ASA on sociodemographic characteristics including age, ethnic background, marital status, education, and employment. The one significant difference was that primigravid women were more likely to have ASA (45\% versus $27.5 \%$; chi-square $=8.587, P=0.003)($ Table 1$)$. The strength of association between parity and the ASA status was further determined using an odds ratio. For mothers with their first pregnancy, the odds of being screened positive for ASA were 2.16 relative to mothers with their second or subsequent pregnancies (Table 2). Impairment data was available for $77.2 \%$ of those who had endorsed ASA symptoms as "fairly often" or "very often." Of these, 32.8\% reported that the symptoms caused them distress or impairment in functioning, representing $7.9 \%$ of the total number of women screened

\section{Discussion}

This study represents the first stage in a program of research examining the novel topic of ASA in pregnancy. The findings suggest that ASA is not uncommon, occurring in a quarter of the women screened. For the majority, ASA symptoms seemed to reflect a general psychological response pattern not associated with dysfunction, but for around one-third of those with ASA, the symptoms were reported to be causing significant impairment in functioning. That proportion was consistent with the observations of the NCS-R study, which 
Table I Sociodemographic characteristics of the sample

\begin{tabular}{|c|c|c|c|c|}
\hline & \multirow[t]{2}{*}{ Total } & \multicolumn{2}{|c|}{ ASA-27 score } & \multirow[t]{2}{*}{ Significance } \\
\hline & & Positive & Negative & \\
\hline Average age in years $(n=331)$ & 29 (range 18-44) & 28.7 (SD 5) & 29.5 (SD 5.7) & $\begin{array}{l}F(I, 329)=0.931 \\
P=0.331\end{array}$ \\
\hline Average weeks pregnant $(n=33 I)$ & 29 (range 8-4I) & 29.3 (SD 7.7) & 29 (SD 7.I) & $\begin{array}{l}\mathrm{F}(\mathrm{I}, 328)=0.123 \\
P=0.729\end{array}$ \\
\hline \multicolumn{5}{|l|}{ Marital status $(\mathrm{n}=327)$} \\
\hline Married/de facto & $81.7 \%$ & $82.3 \%$ & $82.3 \%$ & $X^{2}(2)=0.886$ \\
\hline Single & $14 \%$ & $12.7 \%$ & $14.5 \%$ & $P=0.236$ \\
\hline Separated/divorced & $4.3 \%$ & $7.6 \%$ & $3.2 \%$ & \\
\hline \multicolumn{5}{|l|}{ First time mothers $(n=331)$} \\
\hline First time mother & $31.7 \%$ & $45 \%$ & $27.5 \%$ & $X^{2}(I)=8.587$ \\
\hline Has other children & $68.3 \%$ & $55 \%$ & $72.5 \%$ & $P=0.003^{*}$ \\
\hline \multicolumn{5}{|l|}{ Number of children $(n=331)$} \\
\hline First child & $31.7 \%$ & $45 \%$ & $27.5 \%$ & $X^{2}(3)=9.844$ \\
\hline Second child & $35 \%$ & $23.8 \%$ & $38.6 \%$ & $P=0.02 *$ \\
\hline Third child & $16.9 \%$ & $17.1 \%$ & $17.1 \%$ & \\
\hline Four or more & $16.3 \%$ & $15 \%$ & $16.7 \%$ & \\
\hline \multicolumn{5}{|l|}{ Ethnic background $(n=328)$} \\
\hline Australian & $39.3 \%$ & $35.9 \%$ & $40.3 \%$ & $X^{2}(I)=0.42 I$ \\
\hline Not Australian & $60.7 \%$ & $64.1 \%$ & $59.7 \%$ & $P=0.517$ \\
\hline Asian & $20.6 \%$ & $4.4 \%$ & $19.4 \%$ & \\
\hline Middle Eastern & $16.9 \%$ & $17.9 \%$ & $16.9 \%$ & \\
\hline European & $12.6 \%$ & $7.7 \%$ & $14.1 \%$ & \\
\hline Other Oceanic & $8 \%$ & $12.8 \%$ & $6.5 \%$ & \\
\hline Central/South American & $2.5 \%$ & $1.3 \%$ & $2.8 \%$ & \\
\hline \multicolumn{5}{|l|}{ Education $(\mathrm{n}=328)$} \\
\hline University & $25.6 \%$ & $22.8 \%$ & $26.5 \%$ & $X^{2}(4)=4.713$ \\
\hline TAFE & $25.9 \%$ & $26.6 \%$ & $25.7 \%$ & $P=0.318$ \\
\hline Year I2 (secondary school) & $23.8 \%$ & $31.6 \%$ & $21.3 \%$ & \\
\hline Year I0 (high school) & $20.1 \%$ & $16.5 \%$ & $21.3 \%$ & \\
\hline Other & $4.6 \%$ & $0 \%$ & $5.2 \%$ & \\
\hline \multicolumn{5}{|l|}{ Employment $(n=329)$} \\
\hline Full-time & $23.4 \%$ & $20.3 \%$ & $24.4 \%$ & $X^{2}(3)=0.688$ \\
\hline Part-time & $9.1 \%$ & $10.1 \%$ & $8.8 \%$ & $P=0.142$ \\
\hline Maternity leave & $9.1 \%$ & $8.9 \%$ & $9.2 \%$ & \\
\hline Unemployed & $58.4 \%$ & $60.8 \%$ & $57.6 \%$ & \\
\hline \multicolumn{5}{|l|}{ Occupation $(n=27 I)$} \\
\hline Stay at home mum & $19.9 \%$ & $18.2 \%$ & $20.5 \%$ & $X^{2}(3)=0.180$ \\
\hline Office/administration & $27.7 \%$ & $28.8 \%$ & $27.3 \%$ & $P=0.98 I$ \\
\hline Professionals & $32.8 \%$ & $33.3 \%$ & $32.7 \%$ & \\
\hline Sales/hospitality & $19.6 \%$ & $19.7 \%$ & $19.5 \%$ & \\
\hline
\end{tabular}

Note: $* P<0.05$. ASA-27 Positive and Negative represent participants scoring above or below, respectively, the cutoff score for adult separation anxiety. Abbreviations: ASA-27, Adult Separation Anxiety Scale; SD, standard deviation; TAFE, technical and further education (vocational college).

found that $29.8 \%$ of those classified as having 12 -month ASA reported severe impairment in role functioning. The original receiver operating characteristic analysis in the development of the screening measure and the current finding of convergence with the Composite International Diagnostic Interview diagnosis in a small subset of the sample suggests that the criteria used to identify ASA may be broadly comparable to those applied in the NCS-R study. In this regard, although the sampling approach differed across the two studies, it is noteworthy that the lifetime rates of disabling ASA identified were remarkably similar $-7.9 \%$ in the present study and $6.6 \%$ in the NCS-R for both genders.

The findings, although preliminary, set the stage for future studies that may examine more closely the relationship of pregnancy to ASA: whether pregnancy is a key event that precipitates or exacerbates symptoms; what the trajectory of ASA is through the phases of pregnancy, childbirth, and the postpartum period; and, importantly, what the impact of maternal ASA is on the maternalinfant bond. In evolution, infant separation anxiety has 
Table 2 Parity by adult separation anxiety disorder status

\begin{tabular}{llll}
\hline & \multicolumn{2}{c}{ ASA-27 score } & Total \\
\cline { 2 - 3 } & Positive & Negative & \\
\hline First pregnancy & & & \\
Yes & 36 & 69 & 105 \\
No & 44 & 182 & 226 \\
Total & 80 & 251 & 331 \\
\hline
\end{tabular}

Notes: ASA-27 Positive and Negative represent participants scoring above or below, respectively, the cutoff score for adult separation anxiety. The odds ratio was $(36 / 69) /(44 / 182)=2.16$.

Abbreviation: ASA-27, Adult Separation Anxiety Scale.

been observed to be one of the most strongly conserved behaviors, with this pattern showing continuity into adult life. It is known that separation anxiety disorder is a serious and disabling condition in childhood and when anxiety symptoms persist into adulthood, they are likely to affect relationships and social functioning. ${ }^{13}$ This is pertinent for persons with ASA as they have severe anxiety focused on the safety, wellbeing, and proximity of close attachment figures. A core demand for mothers in the perinatal period involves affiliation with the infant associated with intensive care giving. Hence, the balance in the mother's capacity to maintain proximity and closeness to the infant while at the same time being able to tolerate separations may be pivotal to the way women experience and adapt to this new challenge. ASA may act to undermine this balance by creating anxious forms of attachment. ${ }^{2}$ The finding that ASA was greater in first time mothers is consistent with the expectation that the novelty of pregnancy and associated fears about the safety of the fetus would be greater in this group, but a prospective design is necessary to confirm that possibility.

Given that early mother-infant interactions are crucial in the development and quality of attachment styles, ${ }^{14}$ it is vital to determine whether ASA exerts a specific and potent influence in shaping early mother-infant interaction patterns and infant outcomes. While previous studies have examined women's experience of separation from their infant/child in the form of maternal separation anxiety and its link to adverse infant outcomes (such as sleep and settling problems and the child's later adjustment to kindergarten), ${ }^{15}$ this is the first study to examine the occurrence of ASA as a distinct subtype of adult anxiety identified in the population in general that may interact with the process of pregnancy. Further research is indicated to elucidate the link between ASA and other mental health problems commonly occurring in the perinatal period, such as depression and other forms of anxiety, and its impact on maternal and infant outcomes.

\section{Limitations}

The study was based on a self-report measure making it possible that a clinical diagnostic assessment might have yielded more conservative rates. However, the similarity in rates between this study for a narrowly defined group using information regarding impairment in functioning and those who were identified as having ASA in the NCS-R study seems to suggest that the process of identifying vulnerable women using the screening instrument ASA-27 is a valid approach. As indicated, more needs to be known about the onset, course, and consequences of ASA in pregnancy and its relationship with other anxiety and depressive disorders during pregnancy. Given that there is also some evidence to suggest that separation anxiety may represent a severe form of anxiety with a poor prognosis to standard treatments as compared to other anxiety disorders ${ }^{16}$ there would be value in devising and trialing novel forms of early attachmentbased education in order to promote positive parent-infant interactions in mothers identified as having ASA.

\section{Conclusion}

This first ever study examining the occurrence of ASA in the context of pregnancy observed that this is a common yet unrecognized clinical condition during pregnancy. The study sets the stage for examining whether maternal ASA may result in excessive and maladaptive behaviors to ensure the safety of the infant in the postpartum period, which in turn may have a direct impact on the maternal mental health and infant outcomes. The findings suggest that this adverse outcome may be particularly pertinent in first time mothers. Further research to explore this clinical entity and its impact on the mental health of the mother and the infant is urgently indicated.

\section{Disclosure}

The authors report no conflicts of interest in this work.

\section{References}

1. O'Connor TG, Heron J, Glover V. Antenatal anxiety predicts child behavioral/emotional problems independently of postnatal depression. J Am Acad Child Adolesc Psychiatry. 2002;41(12):1470-1477.

2. Manicavasagar V, Silove D. Is there an adult form of separation anxiety disorder? A brief clinical report. Aust $N Z$ J Psychiatry. 1997;31(2):299-303.

3. Manicavasagar V, Silove D, Curtis J. Separation anxiety in adulthood: a phenomenological investigation. Compr Psychiatry. 1997;38(5): 274-282.

4. Manicavasagar V, Silove D, Curtis J, Wagner R. Continuities of separation anxiety from early life into adulthood. J Anxiety Disord. 2000;14(1): $1-18$.

5. Silove D, Manicavasagar V, Drobny J. Associations between juvenile and adult forms of separation anxiety disorder: a study of adult volunteers with histories of school refusal. J Nerv Ment Dis. 2002;190(6):413-415. 
6. Manicavasagar V, Silove D, Wagner R, Hadzi-Pavlovic D. Parental representations associated with adult separation anxiety and panic disorder - agoraphobia. Aust N Z J Psychiatry. 1999;33(3):422-428.

7. Manicavasagar V, Silove D, Rapee R, Waters F, Momartin S. Parent-child concordance for separation anxiety: a clinical study. $J$ Affect Disord. 2001;65(1):81-84.

8. Shear K, Jin R, Ruscio AM, Walters EE, Kessler RC. Prevalence and correlates of estimated DSM-IV child and adult separation anxiety disorder in the National Comorbidity Survey Replication. Am J Psychiatry. 2006;163(6):1074-1083.

9. Sutter-Dallay AL, Giaconne-Marcesche V, Glatigny-Dallay E, Verdoux H. Women with anxiety disorders during pregnancy are at increased risk of intense postnatal depressive symptoms: a prospective survey of the MATQUID cohort. Eur Psychiatry. 2004;19(8):459-463.

10. Kumar R. Reproduction and psychiatric disorders in women. In: Lader MH, editor. Mental Disorders and Somatic Illness. Cambridge: Cambridge University Press; 1983:62-74.

11. Manicavasagar V, Silove D, Wagner R, Drobny J. A self-report questionnaire for measuring separation anxiety in adulthood. Compr Psychiatry. 2003;44(2):146-153.
12. Silove D, Slade T, Marnane C, Wagner R, Brooks R, Manicavasagar V. Separation anxiety in adulthood: dimensional or categorical? Compr Psychiatry. 2007;48(6):546-553.

13. Barnett B, Parker G. Possible determinants, correlates and consequences of high levels of anxiety in primiparous mothers. Psychol Med. 1986;16(1):177-185.

14. Scher A. Maternal separation anxiety as a regulator of infants' sleep. J Child Psychol Psychiatry. 2008;49(6):618-625.

15. Peleg O, Halaby E, Whaby E. The relationship of maternal separation anxiety and differentiation of self to children's separation anxiety and adjustment to kindergarten: a study in Druze families. J Anxiety Disord. 2006;20(8):973-995.

16. Silove DM, Marnane CL, Wagner R, Manicavasagar VL, Rees S. The prevalence and correlates of adult separation anxiety disorder in an anxiety clinic. BMC Psychiatry. 2010;10:21

\section{Publish your work in this journal}

The International Journal of Women's Health is an international, peerreviewed open-access journal publishing original research, reports, reviews and commentaries on all aspects of women's healthcare including gynecology, obstetrics, and breast cancer. Subject areas include: Chronic conditions (migraine headaches, arthritis, osteoporosis);

\section{Dovepress}

Endocrine and autoimmune syndromes; Sexual and reproductive health; Psychological and psychosocial conditions. The manuscript management system is completely online and includes a very quick and fair peer-review system. Visit http://www.dovepress.com/ testimonials.php to read real quotes from published authors. 